\title{
Consolidating new paradigms in large-scale monitoring and assessment of forest ecosystems
}

\author{
Piermaria Corona* \\ Consiglio per la ricerca in agricoltura e l'analisi dell'economia agraria, Forestry Research Centre, Viale Santa Margherita, 80,52100 Arezzo, Italy
}

\section{A R T I C L E I N F O}

\section{Article history:}

Received 20 January 2015

Received in revised form

6 October 2015

Accepted 15 October 2015

Available online 26 October 2015

\section{Keywords:}

Global changes

Resilience thinking

Complex adaptive system

Forest inventory

Forest mapping

Forest management

\begin{abstract}
A B S T R A C T
Forests provide a wide range of ecosystem services from which people benefit, and upon which all life depends. However, any rational decision related to the maintenance and enhancement of the multiple functions provided by the forests needs to be based on objective, reliable information. As such, forest monitoring and assessment are rapidly evolving as new information needs arise or new techniques and tools become available. Global change issues and utilities from ecosystem management are distinctively to be considered, so that forest inventory and mapping are broadening their scope towards multipurpose resources surveys. Recent changes in forest management perspective have promoted the consideration of forests as complex adaptive systems, thereby highlighting the need to account that such approaches actually work: forest monitoring and assessment are then expected to address and fully incorporate this perspective at global scale, seeking to support planning and management decisions that are evidencebased. This contribution provides selected considerations on the above mentioned issues, in the form of a commented discussion with examples from the literature produced in the last decade.
\end{abstract}

(c) 2015 Elsevier Inc. All rights reserved.

\section{Introduction}

Forests provide a wide range of ecosystem services from which people benefit, and upon which all life depends. The ecosystem service concept has an increasing popularity in contemporary science (e.g. Seppelt et al., 2012) and political commitment (see, e.g., the Millennium Ecosystem Assessment, http://www.millen niumassessment.org/en/Condition.html, and TEEB, 2010). However, any rational decision related to the maintenance and enhancement of the multiple functions provided by the forests needs to be based on objective, reliable information (Corona et al., 2011).

Forest monitoring and assessment are rapidly evolving as new information needs arise or new techniques and tools become available. Two main driving forces are currently stimulating innovation in this field:

1. Technological advances are increasing the capability and costeffectiveness of remote sensing techniques to collect forest data over spatially extensive areas (see e.g. the recent rapid development of satellite and aerial laser scanning to capture threedimensional above-ground information of ecosystems and landscapes).

2. Recent developments in forest management perspective have

\footnotetext{
*Fax: +39 0575353490 .

E-mail address: piermaria.corona@entecra.it
}

led to reconsider the bases of forest ecosystem functioning by embracing new concepts like e.g. resilience thinking (e.g. Walker and Salt, 2006) and complex adaptive system analysis and behavior (e.g. Filotas et al., 2014).

In addition, global change issues and utilities from ecosystem management are distinctively to be considered, so that forest inventory and mapping are broadening their scope towards multipurpose resources surveys. Two major directions can be currently highlighted as: (i) inclusion of additional variables not directly related to timber assessment, wood volume growth and carbon-related issues, like e.g. biodiversity attributes; (ii) extension of the target population to include non-traditional objects, like urban forests and forest trees in non-forest rural landscapes.

This contribution provides selected considerations about recently consolidating paradigms under the above mentioned perspectives in large-scale forest monitoring and assessment, in the form of a commented discussion with examples from the literature produced in the last decade. The following sections are organized upon the following concepts:

1. The methodological focus shifts from deterministic planning, typical of conventional forestry, to learning-based trial and error approaches.

2. The rising relevance of resilience thinking.

3. The need of more rigorous scientific inference. 